\title{
Fluctuation In the Phase Transition Temperature of Poly (NIPAAm-co-HEMA- co-DMAMVA)-Post-guanine Affected by Hydrophilic/hydrophobic Interaction: Fabrication and Characterizations
}

Momen Abdelaty ( $\square$ abdelatymomen@yahoo.com )

Al-Azhar University Faculty of Science https://orcid.org/0000-0002-7442-7053

\section{Research Article}

Keywords: Phase transition temperature, N-isopropylacrlamide, 2-Hydroxyethyl methacrylate, Vanillin derivative, hydrophilic/hydrophobic interaction

Posted Date: November 17th, 2021

DOI: https://doi.org/10.21203/rs.3.rs-1041681/v1

License: @ (i) This work is licensed under a Creative Commons Attribution 4.0 International License. Read Full License 


\section{Abstract}

The phase separation and transition temperature of poly ( $\mathrm{N}$-isopropylacrylamide) have been developed by the terpolymerization with new pH-responsive monomer and highly hydrophilic 2-Hydroxyethyl methacrylate. The new monomer based on vanillin is called 2-((dimethylamino)methyl)-4-formyl-6methoxyphenyl acrylate (DMAMVA), and is investigated by chemical methods $\left({ }^{1} \mathrm{H},{ }^{13} \mathrm{C}\right.$ NMR, FTIR, and mass spectroscopy). Terpolymers of dual-responsive thermo-pH with functional groups were fabricated via free radical polymerization of N-isopropylacrylamide (NIPAAm), 10 mol\% 2-Hydroxyethyl methacrylate (HEMA), and 5, 10, and 20 mol\% DMAMVA. A selected terpolymer was used for post-polymerization with guanine via click reaction and the formation of an imine between the aldehyde group of DMAMVA and the amine group of guanine. All terpolymer and post-terpolymer are chemically evaluated. The physical properties have been implemented by GPC (molecular weight and dispersity), DSC (glass transition temperature $T_{g}$ ), TGA (steps of degradation), and SEM (morphological features). The fluctuations in phase transition temperature $T_{C}$ or the lower critical solution temperature LCST of the polymer solution in different $\mathrm{pH}$ solutions have been performed by two methods, first, the turbidity test by UV-Vis-spectroscopy, second, by micro-DSC for aqueous polymer solution. This work will be extended for more applications in bio-separation technology.

\section{Introduction}

In wake of fast speeding in industrial technology, scientists were striving toward challenging to reveal new material with special properties that can change according to the surrounding environment. Scientists have given it many names among them environmental, smart, stimuli-responsive, and intelligent [1-6]. They have also been discovered in nature e.g., Venus flytrap and Mimosa pudica show responsiveness via electrical and mechanical [7]. According to their responsiveness; it has been classified as mono-responsive such as thermo-responsive [8-10], pH-responsive [11-14], ionic strength [15, 16], mechanical [17], light [18], pressure [19], however, the presence of two or more responsiveness in the same material by copolymerization of different responsive monomers is responsible for creating dual or multiple responsive polymeric material [ 20-25]. One of the most popular kinds of responsive material is polymers that environmentally changed with temperature, and called thermo-responsive polymers. Recently, a researcher has revealed poly $(N$ isopropylacrylamide) (PNIPAAm) to be the most important thermo-responsive polymer, and this is the beginning of research in this area [26-30]. The phase separation temperature of PNIPAAm aqueous solution exhibited lower critical solution temperature LCST $\left(T_{c}\right)$ at about $\sim 32{ }^{\circ} \mathrm{C}$ as reported in many recent publications [31-33]. The transition temperature of PNIPAAm aqueous solution is depending on the balance between hydrophilic groups formed via hydrogen bonds between the amide and carbonyl groups with water, and the hydrophobic groups such as the isopropyl group [31]. By increasing the temperature of the polymer solution, hydrogen bonds begin breaking and decrease the hydrophilicity and consequently increasing in hydrophobicity that improves aggregation and then separation of the polymer molecules from the solution [34], the meanwhile, this behavior is attributed to the change from the isotropic to anisotropic on the basis of Gibbs law [34]. Another responsive material with great interest is pH-responsive; they are functional monomer and polymer that can be ionized to anionic or cationic in $\mathrm{pH}$ solutions producing polymer electrolyte as poly(anions) or poly(cations) [35-37]. In the last few decades, polymer and material scientists have been focused on the fabrication of new materials with dual-responsiveness depending on thermo-pH via copolymerization of PNIPAAm with pH-responsive monomer [38-40]. Moreover, pH-responsive polymers with the tertiary amine functional group have considered the most popular poly (cations) for their wide applications [41]. The copolymerization of poly N-(2-(dimethylaminoethyl) acrylamide) (PDMAEAm) with PNIPAAm has been recently developed for many applications e.g., metal absorption [42], drug delivery [43], bio-separation [44]. In our recent studies, we were interested in the preparation of new monomer based on vanillin as renewable and nontoxic material [45]; these thermo-pHresponsive polymers have been implemented for post-polymerization of amino acids or for improving the phase separation temperature of PNIPAAm [46]. The introduction of hydrophilic or hydrophobic monomers to PNIPAAm has been studied in many recent works [39, 47]. Poly (2-Hydroxyethyl methacrylate) PHEMA is one of the highly hydrophilic polymers; it has several applications, the most important is focused on the fabrication of contact lenses [48-50]. The copolymerization of PNIPAAm with PHEMA was used to achieve hydrophilic-thermo-responsive functional and material, as discussed in many kinds of research [51-53]. This study has also been developed to study the fluctuation in the phase separation temperature or LCST of PNIPAAm as influenced via the terpolymerization with the new $\mathrm{pH}$-monomer contains a hydrophilic tertiary amino group with hydrophobic chain and hydrophilic HEMA. The functional terpolymer has been used in the post-polymerization of amino acids. In the future, the study will focus on new applications for bio-separation technology.

\section{Experimental}

\subsection{Material}

2-Hydroxyethyl methacrylate, 1,2-Ethanediol mono(2-methylpropenoate), Glycol methacrylate, (HEMA, 98\%, Sigma-Aldrich, Germany) was extra-purified by distillation under reduced pressure, 2,2'-Azobis(2-methylpropionitrile) (AIBN, 98\%, Sigma-Aldrich), anhydrous dimethylamine (DMA, 99\%, Sigma-Aldrich), formaldehyde (37 wt\% in water, 10-15\% methanol, Sigma-Aldrich), N-isopropylacrylamide (NIPAAm, 97\%, Acrōs) has been purified by recrystallization from a mixture of benzene/n-hexane 60/40 v/v, Vanillin, 4-Hydroxy-3-methoxybenzaldehyde, (V, 99\%, Sigma-Aldrich), acryloyl chloride or 2-Propenoyl chloride (98 \%, Sigma-Aldrich), guanine (98\%, Sigma-Aldrich). Ethanol, dichloromethane, diethyl ether, and tetrahydrofuran (THF) have been stirred overnight in potassium hydroxide at room temperature and then distilled. Other chemicals were used as purchased.

\subsection{Instrumentation}

Nuclear magnetic resonance (NMR) spectroscopy model Bruker AV 500 has been used for the investigation of ${ }^{1} \mathrm{H}$ and ${ }^{13} \mathrm{C}$ of monomers and polymer molecules. The solid and dried material has been dissolved in deuterated $\mathrm{CDCl}_{3}$ or $\mathrm{DMSO}^{\mathrm{d} 6}$, and then data has been measured at $500 \mathrm{MHz}\left({ }^{1} \mathrm{H}\right)$ and 125 $\mathrm{MHz}\left({ }^{13} \mathrm{C}\right)$. 
Compact ATR-FTIR spectroscopy with the Bruker Alpha has been used for the deduction of functional groups of both monomers and polymers molecules. The sample has been fixed on the surface of a ZnSe ATR crystal and then is functioning as fiber optics. By the entry of the waves of light into the sample; it was exposed to a total reflection. The total attenuated reflected beams were measured and the final results seemed as signals that converted into an infrared spectrum.

ESI/MALDI-TOF mass spectroscopy with modern soft ionization techniques such as electrospray ionization (ESI), the chemical ionization has been done under atmospheric pressure (APCl), and matrix-assisted laser desorption ionization (MALDI) has been used to investigate the ionization of monomer compounds $\mathrm{m} / \mathrm{z}$.

The vario MICRO cube elemental analyzer has been used for estimating the elemental composition of $\mathrm{C}, \mathrm{H}$, and $\mathrm{N}$ of the monomer compounds.

Gel permeation chromatography (GPC) is a technique that used to separate dissolved macromolecules according to their size and depending on their elution through columns filled with a porous gel. It has been used for the determination of the molecular weights including the viscosity average molecular weight $(M v)$, the number average molecular weight $(M n)$, and the weight average molecular weight $(M w)$; dispersity or the formal name the polydispersity index (PDI) and also known as heterogeneity index has been also measured as $M w / M n(\theta)$. We used tetrahydrofuran (THF) as eluent with $2 \mathrm{~g} / \mathrm{L}$ 2,6-di-tert-butyl-4methylphenol (BHT). It was compacted with Jasco 880-PU pump and Waters RI-Detector for justification of the rate of flow at $0.75 \mathrm{ml} / \mathrm{min}$., toluene was the internal standard at $30^{\circ} \mathrm{C}$. Polymers have been dissolved as $6 \mathrm{~g} / \mathrm{L}$ in concentration, and then the injection process was achieved by hand. Standards gel particle PSS-SDV with high-speed polymer service columns has been filled with the porosity of $10^{6} \AA$ (guard), $10^{5} \AA, 10^{3} \AA$, and $10^{2} \AA$ have been respectively used; the molecular weights were detected and recorded related to a narrow polystyrene standard.

Differential scanning calorimeter-DSC Analysis-Netzsch DSC 214 Polymalt has been used to detect the glass transition temperature of solid terpolymers $T_{g}$ 's. it is characterized by the temperature range of 25 to $600{ }^{\circ} \mathrm{C}$, and a heating and cooling rate at 0.001 to $500 \mathrm{~K} / \mathrm{min}$. the glass transition temperature was taken It at the onset value of the thermogram.

Thermogravimetric analysis (TGA) with the Mettler Toledo TGA/SDTA851 was used to elucidate the chemical decomposition as the change of mass with the temperature of polymer sample by heating from $25^{\circ} \mathrm{C}-600{ }^{\circ} \mathrm{C}$ at the rate of $5{ }^{\circ} \mathrm{C} / \mathrm{min}$.

Scanning Electron Microscopy (SEM) Zeiss NEON 40; the change on the surface of the polymer due to the chemical modification has been noticed as the change in the surface morphological features of polymers. It was investigated by Scanning Electron Microscopy (SEM); Zeiss NEON 40, (USA) is the model of the instrument; it is characterized by $2 \mathrm{kV}$ (30 $\mu \mathrm{m}$ aperture), a Bal-tec SCD 500 sputter coater with a film thickness monitor QSG 100. 4 nm and goldpalladium (Au: $\mathrm{Pd}=80: 20$ ).

UV/vis spectrometer (Perkin Elmer Lambda 45)

Two experiments were tested using a UV/VIS spectrometer (Perkin Elmer Lambda 45).

- The estimation of absorption and conversion of polymer to guanine-post-polymer at different pH solutions.

- Measuring of the (LCST) $\left(T_{c^{\prime} s}\right)$ of terpolymers and post-polymer at different pH solutions.

By the test, the instrument was fixed by metal covet, and it has been connected with the water cycle of the water bath with a thermostat and the water pump for both heating and cooling. The manual thermostat (TEMPERATUR-MESSGERÄT MD 3040, BECKMANN+EGLE) placed inside the polymer solution via the rate of $2{ }^{\circ} \mathrm{C} / \mathrm{min}$ in the range of $5-75^{\circ} \mathrm{C}$ has been used to justify the inner temperature; the polymer concentration was $1 \mathrm{wt}$. / wt.\%.

Micro- Differential Scanning Calorimeter (micro-DSC) (Perkin Elmer)

This technique has been used to record the phase transition temperature and the lower critical solution temperatures (LCST) ( $\left.T_{c^{\prime} s}\right)$ of the terpolymers and post-polymer solution. $50 \mathrm{mg} / \mathrm{ml}$ of polymer sample dissolved in DI water; the samples have been exposed to cool and heat at heating rate of $5{ }^{\circ} \mathrm{C} / \mathrm{min}$.; the transition temperature $\left(T_{c}\right)$ was detected at the onset value.

\title{
2.1. Synthesis of pH-responsive acrylate monomer (DMAMVA)-(III) 2- ((dimethylamino)methyl)-4-formyl-6-methoxyphenyl acrylate
}

\author{
Step 1: Synthesis of (DMAMV)-(II) 3-((dimethylamino)methyl)-4-hydroxy-5-methoxy-benzaldehyde
}

Vanillin was used as the start material. $14 \mathrm{~g}$ (0.092 mol) vanillin (4-hydroxy-3-methoxy benzaldehyde), $14 \mathrm{~g}$ (0.310 mol) dimethylamine, and $14 \mathrm{~g}(0.456$ $\mathrm{mol}$ ) formaldehyde were dissolved in $150 \mathrm{ml}$ dry ethanol. The mixture was transferred into a $250 \mathrm{ml}$ two necks round bottom flask fixed with a water condenser and water trap. It was stirred and allowed refluxing for $5 \mathrm{~h}$ at $130{ }^{\circ} \mathrm{C}$; after about $1.5 \mathrm{~h}$ an orange precipitate started till filling the flask. After that, the reaction was stopped and has been kept at RT. The product was concentrated by evaporation of solvent by vacuum rotatory evaporator and then was recrystallized from ethanol. $97.4 \%$, orange solid, melting point $=140{ }^{\circ} \mathrm{C}$

${ }^{1} \mathrm{H} \mathrm{NMR}\left(500 \mathrm{MHz}, \mathrm{CDCl}_{3}\right): \delta(\mathrm{ppm})=2.37\left(\mathrm{~s}, 6 \mathrm{H}, 6-\mathrm{N}\left(\mathrm{CH}_{3}\right)_{2}\right), 3.75\left(\mathrm{~s}, 2 \mathrm{H}, 5-\mathrm{Ar}_{-} \mathrm{NCH}_{2}\right), 3.93(\mathrm{~s}, 3 \mathrm{H}, 3-\mathrm{OCH}), 6.39(\mathrm{br}, 1 \mathrm{H}, 1-\mathrm{OH}), 7.15\left(\mathrm{~d}, 1 \mathrm{H},{ }^{4} \mathrm{~J}=1.8 \mathrm{~Hz}, 9-\right.$ Ar-CH), $7.33\left(\mathrm{~d}, 1 \mathrm{H},{ }^{4} \mathrm{~J}=1.8 \mathrm{~Hz}, 7-\mathrm{Ar}-\mathrm{CH}\right), 9.76(\mathrm{~s}, 1 \mathrm{H}, 11-\mathrm{CHO})$. 
${ }^{13} \mathrm{C}-\mathrm{NMR}\left(125 \mathrm{MHz}_{\mathrm{CDCl}}\right.$ ) $): \delta(\mathrm{ppm})=44.32\left(2 \mathrm{C}, 6-\mathrm{NCH}_{3}\right), 56.01\left(1 \mathrm{C}, 5-\mathrm{NCH}_{2}\right), 62.21\left(1 \mathrm{C}, 3-\mathrm{OCH}_{3}\right), 109.97(1 \mathrm{C}, 9-\mathrm{Ar}-\mathrm{CH}), 123.70$ (1 C, 7-Ar-CH), $125.21(1$ C, 4-Ar-C), 128.09 (1 C, 8-Ar-C), 148.68 (1 C, 2-Ar-C), 154.54 (1 C,10-Ar-C), 190.67 (1 C, 11-CHO).

IR (KBr): v (cm $\left.{ }^{-1}\right)=2450-3100$ (s) $\left(\mathrm{CH}_{2}, \mathrm{CH}_{3}\right), 2056-2341$ (s) (C-N), 1735 (s) (C=0), 1660 (s) (Ar-C-0), 1575 (s) (Ar-C=C), 1112 (s) (-OCH3), $814-847$ (m) (Ar$\mathrm{CH})$.

MS $m / z(\%)$

$209.11\left[\mathrm{M}^{+}\right], 100 \%$

Anal. Calcd. For $\mathrm{C}_{11} \mathrm{H}_{15} \mathrm{NO}_{3}$ (209.11): Calc. (\%): C, 63.14; $\mathrm{H}, 7.23 ; \mathrm{N}, 6.69 ;$ Found (\%): C, 62.92; H, 7.34; N, 6.23

Step 2: Synthesis of compound (III) 2-((dimethylamino)methyl)-4-formyl-6-methoxyphenyl acrylate (DMAMVA).

The final product of the new acrylate monomer (DMAMVA)-(III) can be s synthesized by the addition of $7.5 \mathrm{~g}$ (0.0355mol) (DMAMV)-(II) and 7.5 $\mathrm{g}$ (0.187mol) sodium hydroxide into $100 \mathrm{ml}$ dry dichloromethane and transferred into $250 \mathrm{ml}$ three-neck flask equipped with dropping funnel, water condenser, and a balloon of argon. The reaction mixture has been allowed to stir in an inert atmosphere. The reaction was cooled to $0-5{ }^{\circ} \mathrm{C}$ in an ice bath, and then $3.23 \mathrm{~g}$ ( $0.0355 \mathrm{~mol}$ ) acryloyl chloride dissolved in $15 \mathrm{ml}$ dichloromethane was dropped to the reaction mixture by the dropping funnel and during vigorous stirring. The suspension converted to yellow color on the edges of the flask; the stirring was continued at $0-5^{\circ} \mathrm{C}$ for about $1 \mathrm{~h}$ until the yellowish precipitate was dominated. After this step, the reaction was left at room temperature for 6 h.; it was filtered and the solvent was removed. The purification steps was carried out by dissolving in $\mathrm{CH}_{2} \mathrm{Cl}_{2}$ and washing several times with deionized water, and then washing with $0.1 \mathrm{M} \mathrm{Na}_{2} \mathrm{CO}_{3}$ solution, and washed two times again with $\mathrm{DI} \mathrm{H}_{2} \mathrm{O}$. It was separated by the separated funnel, and the organic phase was dried overnight via $\mathrm{MgSO}_{4}$. The product was concentrated by evaporation of the solvent and the final pure product was collected for further analysis and application. $75 \%$, orange viscous liquid.

$\left.{ }^{1} \mathrm{H} \mathrm{NMR}\left(500 \mathrm{MHz}, \mathrm{CDCl}_{3}\right): \delta(\mathrm{ppm})=2.19\left(\mathrm{~s}, 6 \mathrm{H}, 13-2 \mathrm{CH}_{3}\right), 3.37\left(\mathrm{~s}, 2 \mathrm{H}, 12-\mathrm{NCH}_{2}\right), 3.84\left(\mathrm{~s}, 3 \mathrm{H}, 6-0 \mathrm{CH}_{3}\right), 6.03\left(\mathrm{dd},{ }^{2} \mathrm{~J}=1.1 \mathrm{~Hz},{ }^{3} \mathrm{~J}=10.5 \mathrm{~Hz}, 1 \mathrm{H}, 1-\mathrm{Hb}=\mathrm{CH}\right)\right)$, $6.34\left(\mathrm{dd},{ }^{3} \mathrm{~J}=10.5 \mathrm{~Hz},{ }^{3} \mathrm{~J}=17.3 \mathrm{~Hz}, 1 \mathrm{H}, 2-\mathrm{Hc}=\mathrm{CH}\right), 6.64\left(\mathrm{dd},{ }^{2} \mathrm{~J}=1.1 \mathrm{~Hz},{ }^{3} \mathrm{~J}=17.3 \mathrm{~Hz}, 1-\mathrm{Ha}=\mathrm{CH}_{2}\right), 7.37\left(\mathrm{~d}, 1 \mathrm{H},{ }^{4} \mathrm{~J}=1.7 \mathrm{~Hz}, 7-\mathrm{Ar}-\mathrm{CH}, 7.34\left(\mathrm{~d}, 1 \mathrm{H},{ }^{4} \mathrm{~J}=1.7 \mathrm{~Hz}\right.\right.$, 10-Ar-CH), 9.91 (s,1 H, 9-CHO).

${ }^{13} \mathrm{C}-\mathrm{NMR}\left(125 \mathrm{MHz}, \mathrm{CDCl}_{3}\right): \delta$ (ppm) = $45.42\left(2 \mathrm{C}, 13-2 \mathrm{CH}_{3}\right), 55.72\left(1 \mathrm{C}, 12-\mathrm{NCH}_{2}\right), 62.41\left(1 \mathrm{C}, 6-\mathrm{OCH}_{3}\right), 108.75(1 \mathrm{C}, 7-\mathrm{Ar}-\mathrm{CH}), 122.37(1 \mathrm{C}, 11-\mathrm{Ar}-\mathrm{CH}), 126.25$ (1 C,2=CH), 127.30 (1 C, 10-Ar-C), 132.22 (1 C, 1=CH $)$, 134.39 (1 C, 8-Ar-C), 143.50 (1 C, 4-Ar-C), 152.51 (1 C, 5-Ar-C), 162.81 (1 C, 3-COO), 191.64 (1 C, 9$\mathrm{CHO})$.

IR (KBr): v (cm $\left.{ }^{-1}\right)=2400-3120$ (s) $\left(\mathrm{CH}_{2}, \mathrm{CH}_{3}\right), 2058-2450$ (s) (C-N), 1760 (s) (ester C=0), 1745(s) (aldehyde C=0), 1665 (s) (Ar-C-0), 1587 (s) (Ar-C=C), 1120 (s) (-OCH3), $820-860(\mathrm{~m})(\mathrm{Ar}-\mathrm{CH})$.

MS m/z (\%)

$263.12\left[\mathrm{M}^{+}\right], 100 \%$

Anal. Calcd. For $\mathrm{C}_{14} \mathrm{H}_{17} \mathrm{NO}_{4}$ : Calc. (\%): C, 63.87; H, 6.51; N, 5.32;; Found (\%):C, 63.22; H, 5.97; N, 5.17

\subsection{Synthesis of poly ( $N$-isopropylacryamide-co-2-Hydroxyethyl methacrylate-co-2- ((dimethylamino)methyl)-4-formyl-6-methoxyphenyl acrylate) poly (NIPAAm-co-HEMA- co-DMAMVA) thermo-pH stimuli-responsive terpolymer}

The reaction has been done three times with different molar concentrations of DMAMVA 5,10 and $20 \mathrm{~mol} \%(0.0013 \mathrm{~mol} / 0.342 \mathrm{~g}),(0.00265 \mathrm{~mol} / 0.697 \mathrm{~g})$ and $(0.0053 \mathrm{~mol} / 1.697 \mathrm{~g})$ respectively, and $10 \mathrm{~mol} \%$ of HEMA $(0.00265 \mathrm{~mol} / 0.345 \mathrm{~g})$, and $(0.0265 \mathrm{~mol} / 3 \mathrm{~g})$ of N-isopropylacrylamide and AlBN initiator $\left(10^{-3}\right.$ of the total molar concentrations of monomers); they were dissolved in $60 \mathrm{ml}$ absolute ethanol. The three mixtures were reacted in $100 \mathrm{ml}$ round bottom flasks fitted with rubber stoppers allowed for nitrogen injection. They allowed stirring in an oil bath for $6 \mathrm{~h}$ at $75^{\circ} \mathrm{C}$. After the specific time has finished the polymerization reaction has been terminated by cooling firstly at room temperature and then in the refrigerator. The terpolymers were precipitated in diethyl ether, at $-20^{\circ} \mathrm{C}$; they have been extra purified to remove the small molecules by dissolving in THF and again re-precipitated in Et2O. They were crystals varied in color from white to light yellow to yellow depending on the concentration of DMAMVA.

${ }^{1} \mathrm{H} \mathrm{NMR}_{(500} \mathrm{MHz}_{\mathrm{CDCl}}$ ) $): \delta(\mathrm{ppm})=0.95-1.22\left(\mathrm{~m}, 12 \mathrm{H}, 6,12-2 \mathrm{CH}_{3}\right), 1.25-1.62(\mathrm{~m},-\mathrm{CH}$ - repeating unit), 1.83-2.22 (m, 3H, 9-CH $), 3.42-3.47(\mathrm{~m}, 2 \mathrm{H}, 5-\mathrm{CH})$, 3.53-3.59 (m, 3H, 4- $\left.\mathrm{CH}_{3}\right), 3.60-3.68\left(\mathrm{~m}, 2 \mathrm{H}, 7-\mathrm{CH}_{2}\right), 3.73-4.05(\mathrm{~m}, 1 \mathrm{H}, 11-\mathrm{CH}), 4.74-5.22\left(\mathrm{~m},-\mathrm{CH}_{2}\right.$-repeating unit), 6.72-7.84 (m, 3H, 10-NH, 2,3-Ar- $\left.\mathrm{H}\right), 9.85-$ $10.07(\mathrm{~m}, 1 \mathrm{H}, 1-\mathrm{CHO})$.

IR (KBr): v (cm ${ }^{-1}$ ): 3254-3662 (N-H, OH), 3760-3100 (CH-Aliphatic), 1764 (s) (C=0, carbonyl), 1728 (s) (C=0, aldehyde), 1565, (s) (C=0 amide), 1110 (m) $\left(\mathrm{OCH}_{3}\right), 877(\mathrm{~m})(\mathrm{CH}-\mathrm{Ar}$.$) .$

\subsection{Synthesis of poly (NIPAAm-co-HEMA-co-DMAMVA)-post-guanine}


The post-polymerization of poly (NIPAAm-co-HEMA-co-DMAMVA) with guanine has been achieved according to Schiff base reaction mechanism. The terpolymer $\mathrm{VI}-10-10$ was selected for implementing. The reaction between terpolymer and guanine was performed in different $\mathrm{pH}$ solutions $\mathrm{pH} 3$, $\mathrm{pH} 7$ and $\mathrm{pH} 12$. In three $50 \mathrm{ml}$ round bottom flasks $1 \mathrm{~g}$ of the terpolymer $\mathrm{Vl}-10-10$ was added to $(0.013 \mathrm{~mol} / 2 \mathrm{~g})$ of guanine were dissolved in $30 \mathrm{ml} \mathrm{pH}$ solutions. They allowed stirring for $6 \mathrm{~h}$ at RT. The brownish precipitate start appears after $2 \mathrm{~h}$; the reaction continued till the limited time and then stopped and separated off. The precipitate was filtered, and then dissolved in THF and precipitated in diethyl ether at $-20^{\circ} \mathrm{C}$. The product was dark brownish crystals.

${ }^{1} \mathrm{H} \mathrm{NMR}\left(500 \mathrm{MHz} \mathrm{CDCl}_{3}\right): \delta(\mathrm{ppm})=0.96-1.51\left(\mathrm{~m}, 12 \mathrm{H}, 9,18-2 \mathrm{CH}_{3}\right), 1.53-1.66\left(\mathrm{~m}, 3 \mathrm{H}, 12-1 \mathrm{CH}_{3}\right), 1.65-1.95(\mathrm{~m}, 2 \mathrm{H}, 10,14-\mathrm{CH}$ repeating), 2.08-2.75 $(\mathrm{m}, 6 \mathrm{H}$, $11,13,15-3 \mathrm{CH}_{2}$ repeating), 3.45-3.56 $\left(\mathrm{m}, 3 \mathrm{H}, 7-1 \mathrm{CH}_{3}\right), 3.52-3.83\left(\mathrm{~m}, 2 \mathrm{H}, 20-1 \mathrm{CH}_{2}\right), 3.87-3.93\left(\mathrm{~m}, 2 \mathrm{H}, 19-1 \mathrm{CH}_{2}\right), 4.02-4.17(\mathrm{~m}, 1 \mathrm{H}, 17-\mathrm{CH}), 4.85-5.36(\mathrm{~m}, 1 \mathrm{H}, 2-$ $\mathrm{CH}), 5.90-6.10(\mathrm{~m}, 1 \mathrm{H}, 3-\mathrm{NH}), 6.13-6.73(\mathrm{~m}, 1 \mathrm{H}, 17-\mathrm{NH}), 6.79-7.20(\mathrm{~m}, 1 \mathrm{H}, 5-\mathrm{Ar}-\mathrm{H}), 7.30-7.48(\mathrm{~m}, 1 \mathrm{H}, 5-\mathrm{Ar}-\mathrm{H}), 8.05-8.23(\mathrm{~m}, 1 \mathrm{H}, 4-\mathrm{CH}=\mathrm{N}), 12.46-12.75(\mathrm{~m}, 1 \mathrm{H}, 1-$ $\mathrm{NH})$.

IR (KBr): v (cm ${ }^{-1}$ ): 3430-3640 (s) (NH, OH), 2988-3185(m) (CH-Aliphatic), 1640-1647 (s) (C=0), 1556-1560 (s) (-CH=N), 1095-1113 (s) (OCH $)$

\section{Results And Discussions}

\subsection{Synthesis of a new pH-responsive monomer}

One of the most important applications of vanillin is the formation of vanillin-based monomers. A new strategy for the formation of a new acrylate functional monomer based on vanillin as a natural material has been achieved in this study. A new stimuli-responsive acrylate monomer for the pHresponsive has been synthesized from vanillin (4-hydroxy-3-methoxybenzaldehyde) in two steps as described in Scheme 1. The first step was used for synthesizing the pre-monomer compound and the formation of a tertiary amine group that is responsible for the $\mathrm{pH}$-responsiveness of the whole monomer and consequently polymers. It has been done by reacting vanillin with formaldehyde and dimethylamine in an alkaline solution. This reaction is proceeding according to the Mannich reaction mechanism. The new compound 3-((dimethylamino)methyl)-4-hydroxy-5-methoxy-benzaldehyde (DMAMV) (II) has been evaluated by ${ }^{1} \mathrm{H}$ NMR, ${ }^{13} \mathrm{C}$ NMR, FT IR, mass spectroscopy, and elemental analysis. Figure 1 and 2 show the ${ }^{1} \mathrm{H}$ NMR and ${ }^{13} \mathrm{C}$ NMR, respectively, the first demonstrated the presence of dimethylamine group $-\mathrm{N}\left(\mathrm{CH}_{3}\right)_{2}$ at $\delta=2.73 \mathrm{ppm}$ and methylene $\mathrm{Ar}-\mathrm{CH}_{2} \mathrm{~N}$ - at $\delta=3.75$ ppm, moreover, other protons related to vanillin have been detected such as $-\mathrm{OH}$ at $\delta=6.39 \mathrm{ppm}, \mathrm{H}-\mathrm{CHO}$ at $\delta=9.76 \mathrm{ppm}$; the aromatic ring showed two protons at $\delta=7.15 \mathrm{ppm}$ and $7.33 \mathrm{ppm}$, however, the third proton has been disappeared for the formation of methylene tertiary amine group $-\mathrm{CH}_{2} \mathrm{~N}\left(\mathrm{CH}_{3}\right)_{2}$. The ${ }^{13} \mathrm{C} \mathrm{NMR}$ indicates the addition of a new group to vanillin by the presence of peaks at $\delta=44.32$ and $56.01 \mathrm{ppm}$ for $-\left(\mathrm{CH}_{3}\right)_{2}$ and $-\mathrm{CH}_{2} \mathrm{~N}$-, respectively, and $\delta=190.67 \mathrm{ppm}$ for the carbon atom of the aldehyde group. The final product is 2-((dimethylamino)methyl)-4-formyl-6-methoxyphenyl acrylate (DMAMVA) (III); it has been obtained by reacting compound (II) with acryloyl chloride in an alkaline solution as illustrated in Scheme 1; the first hour was done in an ice bath due to an exothermic behavior. The reaction has been performed, and the product has purified and then investigated. The ${ }^{1} \mathrm{H},{ }^{13} \mathrm{C}$ NMR was successfully used to evaluate the protons and their corresponding carbons; they proved the formation of $3 \mathrm{H}$ of the vinyl acrylate group $-\mathrm{CH}=\mathrm{CH}_{2}$ at $\delta=6.03,6.34$, and 6.64 ppm via $2 \mathrm{C}$ at $\delta=126.25$ and $132.22 \mathrm{ppm}$; another proton $1 \mathrm{H}-\mathrm{CHO}$ at $\delta=9.91 \mathrm{ppm}$ and ${ }^{13} \mathrm{C}$ at $\delta=191.64 \mathrm{ppm}$. Other protons and carbon atoms have also been deduced as shown in Figures 3 and 4. The FT IR has used for investigating the absorbance of functional groups as illustrated in Figure 7; for compound (II) such as v = 2450, and $1735 \mathrm{~cm}^{-1}$ due to $\mathrm{C}-\mathrm{N}\left\{-\mathrm{H}_{2} \mathrm{C}-\mathrm{N}\left(\mathrm{CH}_{3}\right)_{2}\right\}$ and $-\mathrm{C}=\mathrm{O}$ aldehyde. However, compound (III) recorded the absorbance at v=2500, 1760, 1745, and $1665 \mathrm{~cm}^{-1}$ for $\mathrm{C}-\mathrm{N}$, $\mathrm{C}=\mathrm{O}$ ester, $\mathrm{C}=\mathrm{O}$ aldehyde, and $\mathrm{C}=\mathrm{C}$ vinyl. Further, certainty of the evaluation of compound (II) by MALDI-TOF mass spectrometry has been done and recorded the molecular ion peak at m/z 209.11 with $100 \%$ abundance. Also, elemental analysis was performed and indicated logical results to the calculated mass percentage of each $\mathrm{C}, \mathrm{H}$, and $\mathrm{N}$ atoms.

The new synthetic monomer has been used in the formation of a series of functional and pH-thermo-responsive terpolymers (VI-10-05, VI-10-10, and VI-1020), which is achieved by our first goal of that study. Random free radical polymerization has been used for the polymerization process of the new monomer (DMAMVA) as a functional pH-responsive, with N-isopropylacrylamide (NIPAAm) acting as a thermo-responsive monomer and 2-Hydroxyethyl methacrylate (HEMA) as a function with a highly hydrophilic monomer. The polymerization was established depending on the change of molar concentration of (DMAMVA) 5, 10, and $20 \mathrm{~mol} \%$, and $10 \mathrm{~mol} \%$ of (HEMA) dependent of (NIPAAm), it was done in solution and using AIBN as an initiator. Polymers have been evaluated by ${ }^{1} \mathrm{H}$ NMR and FT IR. By the ${ }^{1} \mathrm{H}$ NMR Figure 5, the spectra demonstrated the most specific multiple peaks of monomers e.g. for NIPAAm, at $\delta=$ 0.95-1.22 ppm related to isopropyl - $\left(\mathrm{CH}_{3}\right)_{2}$, and $\delta=3.73-4.05 \mathrm{ppm}$ to isopropyl $-\mathrm{CH}-$, however, HEMA demonstrated the presence of methyl group at $\delta=1.83-$ $2.22 \mathrm{ppm}$. The third monomer DMAMVA has also been represented three specific peaks at $\delta=3.42-3.47 \mathrm{ppm}, 6.72-7.84 \mathrm{ppm}$, and 9.85-10.07 ppm for the methylene group $-\mathrm{CH}_{2} \mathrm{~N}$-, aromatic protons and aldehyde proton, respectively. The FT IR investigation illustrated the absorption of the most important functional groups such as carbonyl ester and aldehyde; they have appeared at $v=1745$, and $1728 \mathrm{~cm}^{-1}$ respectively, as shown in Figure 7 . Eventually, the application of terpolymer by selecting $\mathrm{Vl}-10-10$ to achieve the click reaction and post-polymerization with guanine has been done. The reaction conditions were changed from acidic, neutral, and then alkaline to obtain the best conversion of terpolymer-post-guanine as shown in Figure 8; we observed that the alkaline solution was the best to perform the reaction in the best conversion at $78 \%$. As we used previously, for the investigation we used ${ }^{1} \mathrm{H}$ NMR and $\mathrm{FT}$ IR; we noticed the formation of the imine group at $\delta=8.05-8.23 \mathrm{ppm}$ corresponding to its absorption at $\mathrm{v}=1560 \mathrm{~cm}^{-1}$ as shown in Figures 6 and 8 . 
Table 1

Yield, composition, molecular weight, dispersity, glass temperature and transition temperature of poly(NIPAAm-co- HEMA-co- DMAMVA) and poly(NIPAAmco- HEMA-co- DMAMVA)-post-guanine.

\begin{tabular}{|c|c|c|c|c|c|c|c|c|c|c|c|c|c|}
\hline \multirow[t]{2}{*}{ Polymer } & \multirow{2}{*}{$\begin{array}{l}\text { Yield } \\
\text { (\%) }\end{array}$} & \multicolumn{2}{|c|}{$\begin{array}{l}\text { Composition } \\
{ }^{1} \mathrm{HNMR}\end{array}$} & \multirow{2}{*}{$\begin{array}{l}\mathrm{Mn}^{\mathrm{a}} \\
(\mathrm{g} / \mathrm{mol}) \\
10^{4}\end{array}$} & \multirow{2}{*}{$\begin{array}{l}\mathrm{Mw}^{\mathrm{b}} \\
\\
(\mathrm{g} / \mathrm{mol}) \\
10^{4}\end{array}$} & \multirow[t]{2}{*}{$\oplus^{c}$} & \multirow[t]{2}{*}{$\begin{array}{l}\mathrm{T}_{g}{ }^{\mathrm{d}} \\
\left({ }^{\circ} \mathrm{C}\right)\end{array}$} & \multicolumn{5}{|c|}{$\begin{array}{l}\mathrm{T}_{c}{ }^{\mathrm{e}}\left({ }^{\circ} \mathrm{C}\right) / \mathrm{C}_{p}{ }^{\mathrm{f}}\left({ }^{\circ} \mathrm{C}\right) \\
\text { UV-VIS }\end{array}$} & \multirow{2}{*}{$\begin{array}{l}\mathrm{T}_{c}^{\mathrm{e}} \\
\left({ }^{\circ} \mathrm{C}\right) \\
\mathrm{DSC}\end{array}$} \\
\hline & & DMAMVA & HEMA & & & & & pH 1.68 & pH 3 & $\mathrm{pH} 7$ & pH 10.4 & pH 12 & \\
\hline VI-10-05 & 84 & 3.25 & 8.46 & 5.93 & 11.56 & 1.95 & 146.7 & $36.7 / 37.5$ & $36.5 / 37.3$ & $34.3 / 35.3$ & $33.9 / 34.7$ & $32.8 / 33.5$ & 33.6 \\
\hline VI-10-10 & 82 & 6.66 & 8.58 & 5.45 & 10.79 & 1.98 & 142.4 & $40.8 / 41.6$ & $40.2 / 41.4$ & $28.7 / 29.5$ & $27.8 / 28.9$ & $26.6 / 27.8$ & 27.5 \\
\hline VI-10-20 & 78 & 12.63 & 8.35 & 4.85 & 10.67 & 2.20 & 132.5 & $48.5 / 49.3$ & $47.8 / 48.7$ & $21.5 / 22.6$ & $20.3 / 21.5$ & $19.7 / 22.0$ & 19.3 \\
\hline VIII & 63.8 & - & - & 2.72 & 6.75 & 2.48 & 125.2 & $39.5 / 40.4$ & $39 / 39.8$ & $25.2 / 26.7$ & $22.4 / 23.5$ & $22.3 / 23.6$ & 23.8 \\
\hline
\end{tabular}

a number average molecular weight;

b weight average molecular weight;

${ }^{\mathrm{c}}$ dispersity;

${ }^{\mathrm{d}}$ glass transition temperature;

e lower critical solution temperature;

${ }^{f}$ cloud point.

\subsection{Miscellaneous physical characterizations of poly(NIPAAm-co-HEMA-co-DMAMVA) and poly(NIPAAm-co-HEMA-co-DMAMVA)-post-guanine}

Gel permeation chromatography (GPC) has been used to measure the molecular weights (number average molecular weight $M_{n}$, and weight average molecular weight $M_{w}$ ) further the dispersity $(\bigotimes)$ of the polymer solutions. The process was performed as described in detail previously; they dissolved in tetrahydrofuran THF ( $6 \mathrm{~g} / \mathrm{L}$ and containing $0.2 \mathrm{~g} / \mathrm{L}$ of BHT). Samples of terpolymers poly(NIPAAm-co-HEMA-co-DMAMVA) (VI-10-05, VI-10-10, and VI-10-20), and post-terpolymer poly(NIPAAm-co-HEMA-co-DMAMVA)-post-guanine (VIII). The GPC analysis was recorded, and the chromatograms were drawn for all polymers as seen in Figure 9. We recorded some observations; first, the influence of the molar concentration of DMAMVA on both of the number average molecular weights $M_{n}, M_{w}$ and the dispersity $\nabla$ of terpolymers demonstrated decreasing in $M_{n}(5.93,5.45$, and 4.85$) 10^{4} \mathrm{~g} / \mathrm{mol}$, and $M_{w}(11.56,10.79$, and

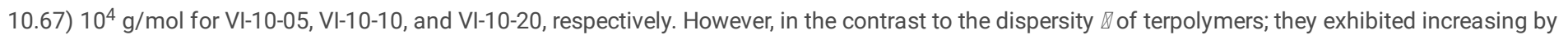
increasing the molar concentrations of DMAMVA in the terpolymer main chain; they recorded 1.95, 1.98, and 2.20, respectively. Moreover, the lowest $M_{n}$ and

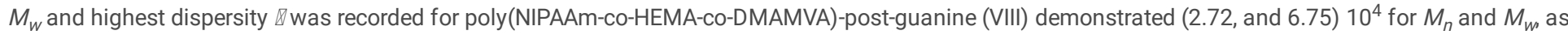

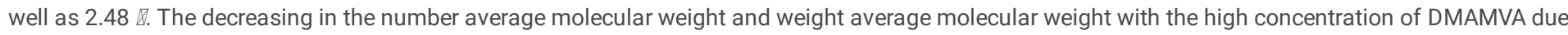
to the steric hindrances of aromaticity in the terpolymer main chain; the maximum effect was noticed with the poly(NIPAAm-co-HEMA-co-DMAMVA)-postguanine (VIII) with the high aromaticity [32]. The next observation has occurred in the formation of chromatograms with single peaks, which interpreted by the disappearance of molecules that have low molecular weights e.g. monomers and impurities [30], all data has been summarized in Table 1.

The thermal characterizations of terpolymers and post-terpolymer have been distinguished by two methods. One of them has been used for recording the glass transition temperature $T_{g^{\prime}} s$ of the solid polymer, and has been performed by differential scanning calorimetry (DSC). The measurements of the glass temperature of poly(NIPAAm-co-HEMA-co-DMAMVA) (VI-10-05, VI-10-10, and VI-10-20), and post-terpolymer poly(NIPAAm-co-HEMA-co-DMAMVA)-postguanine (VIII) have been conducted on the dry samples at $5^{\circ} \mathrm{C} / \mathrm{min}$ and in an inert atmosphere. Figure 10 exposes the diffractogram of terpolymers and post-terpolymer with guanine as the relationship between temperature and heat flow. The glass transition temperatures $T_{g}$ 's have been taken at the onset value and declared $146.7,142.4$, and $132.5^{\circ} \mathrm{C}$ for $\mathrm{VI}-10-05, \mathrm{VI}-10-10$, and $\mathrm{VI}-10-20$, respectively. An opposite relation with the molar concentration of DMAMVA was observed, as the lower concentration of DMAMVA in the terpolymer main chain, the higher the glass temperature. This behavior is attributed to the balance between the hydrophilic/hydrophobic groups in the polymer main chain, which showed the domination of hydrophobicity effect at the higher concentration of DMAMVA, however, at low concentration, the terpolymer has fully influenced by the hydrophilic groups located in NIPAAm and HEMA as well $[32,39]$. By post-polymerization in poly(NIPAAm-co-HEMA-co-DMAMVA)-post-guanine (VIII), the glass transition temperature $T_{g}$ was recorded at 125.2 ${ }^{\circ} \mathrm{C}$ that exhibited the lowest $T_{g}$ compared to terpolymers $\mathrm{VI}-10-05, \mathrm{VI}-10-10$, and $\mathrm{VI}-10-20$; it can be interpreted as discussed previously, in addition to the effect of hydrophobic groups in the guanine molecule, which directly affected on the whole polymer chain.

Another technique has been performed to investigate the thermal properties of terpolymers and post-terpolymer; we used the thermogravimetric analysis (TGA) for describing the thermal degradation steps by changing the mass percentage with temperature. The process has been conducted on terpolymers VI10-05, VI-10-10, and VI-10-20, and post-terpolymer VIII. Figure 11A and B show the thermogram of polymers TG and their first derivative DTG. They demonstrated a series of thermal degradation, first at 100-120 ${ }^{\circ} \mathrm{C}$ for evaporation of moisture content. The onset degradation temperature $T_{\text {onset }}$ has been appeared as one onset by VI-10-05 at $237^{\circ} \mathrm{C}$, two for VI-10-10 $238^{\circ} \mathrm{C}$ and 337 , three for VI-10-20 at 238 , 286, and $342{ }^{\circ} \mathrm{C}$; while post-terpolymer exhibited 
multiple $T_{\text {onset }}$ at $233,272,266$, and $297^{\circ} \mathrm{C}$. They demonstrated lower homogeneity of terpolymer by increasing the molar concentration of DMAMVA in the polymer main chain, further, the lowest one was observed for post-terpolymer [39, 55]. The main degradation has occurred at $273,399,396$, and $374{ }^{\circ} \mathrm{C}$ for terpolymers and post-terpolymer. The final degradation and fully degradation were observed for all terpolymer and post-terpolymer at $537-558{ }^{\circ} \mathrm{C}$; it clues a decrease of fully thermal degradation by increasing in molar concentration of DMAMVA in the polymer main chain.

The morphological features of terpolymer before VI-10-10 and after post-polymerization VIII were performed by scanning electron microscopy (SEM). The process was conducted on dry polymer samples that were pressed into small disks. The scanning has been performed at $750 x$ magnification. The scanning appeared some images, as shown in Figure 12; it exhibits waxy and coarse for terpolymer before post-polymerization, while, after post-polymerization and the chemical modification it seems as waxy and compact.

\section{Phase separation properties and lower critical solution temperature $\left(T_{c}\right)$ of poly(NIPAAm-co-HEMA-co-DMAMVA) and poly(NIPAAm-co-HEMA-co- DMAMVA)-post-guanine as $\mathrm{pH}$ dependent}

Eventually, we are going to our main target of studying the lower critical solution temperature of terpolymers solutions and explorer how the chemical structure of terpolymers and the chemical modifications by post-polymerization have affected the fluctuations of the LCST ( $T_{c}$ s $s$ ). The test has been performed by two methods. First, UV-Vis-spectroscopy has been implemented three times, and the mean value has been considered. The technique depends on the turbidity of the solution by measuring the transmittance via temperature change in different pH solutions. Figure $13 \mathrm{~A}$ showed the lower critical solution temperature $\left(T_{c^{\prime}} s\right)$, and the cloud points $\left(C_{p^{\prime}} s\right)$ of terpolymers $\mathrm{VI}-10-05, \mathrm{VI}-10-10$, and $\mathrm{VI}-10-20$ at $\mathrm{pH} 1.68$ demonstrated $36.7,40.8$, and $48.5^{\circ} \mathrm{C}$ for $T_{c^{\prime}} S$, as well as the corresponding $C_{p}$ s at $37.5,41.6$, and $49.3^{\circ} \mathrm{C}$, respectively. The gradual rise in the transition temperature and the cloud point is due to the domination of the hydrophilic effect created by highly ionization and protonation of the tertiary amine group in DMAMVA; the slight decrease in each of $T_{c}$ and $C_{p}$ of VI-10-10-post-guanine VIII at 39.5, and $40.4{ }^{\circ} \mathrm{C}$, respectively; it is attributed to an additional hydrophobic affected by guanine molecule [54]. At pH3 as shown in Figure13B; it demonstrated closed results of pH1.68; the $T_{c^{\prime}} s\left(36.5,40.2\right.$, and $\left.47.8^{\circ} \mathrm{C}\right)$, and $C_{p^{\prime}} s\left(37.3,41.4\right.$, and $\left.48.7{ }^{\circ} \mathrm{C}\right)$ for $\mathrm{VI}-10-05$, VI-10-10, and VI-10-20, respectively, the data proofed the similarity of conditions that the terpolymer has been exposed. Further, the post-terpolymer exhibited $T_{C}$ and $C_{p}$ at 39.0 , and $39.8^{\circ} \mathrm{C}$ for the same reason discussed previously. By increasing the $\mathrm{pH}$ of terpolymer solution reaching to the neutral conditions in $\mathrm{pH} 7 \mathrm{as}$ shown in Figure 13C; we observed sharp fluctuation in the $T_{c}^{\prime} s$ and $C_{p}$ s demonstrated $\left(34.3,28.7\right.$, and $\left.21.5^{\circ} \mathrm{C}\right)$ and $\left(35.3,29.5\right.$, and $\left.26.7^{\circ} \mathrm{C}\right)$; it exhibited sharply decreased by increasing the molar concentration of DMAMVA in the terpolymer main chain, indicating the domination of the hydrophobic groups than the hydrophilic one, rather than steric hindrances occurred in the polymer molecule [32]. Also, post-terpolymer VIII exhibited 25.2 and $26.7^{\circ} \mathrm{C}$ for $T_{C}$ and $C_{p}$ lower than VI-10-10; the interpretation has still attributed to the hydrophobic groups in guanine and the highly steric hindrances and restricted free rotation of polymer molecule [54]. Meanwhile, the effect of the alkaline solution on the phase separation temperature has also been considered in the middle $(\mathrm{pH} 10.06)$ and strong $(\mathrm{pH} 12)$ solutions. The transition temperature and cloud point of terpolymers and post-terpolymer in $\mathrm{pH} 10.04$ demonstrated lower values for each $T_{c^{\prime}} s$, and $C_{p^{\prime}} s$ than results due to $\mathrm{pH}$; they were at $33.9,27.8,20.3$, and $22.3^{\circ} \mathrm{C}$ of $T_{c^{\prime}} s$, and $C_{p^{\prime}} s$ at $34.7,28.9,21.5$, and 23.6 for all terpolymers (VI-10-05, VI-10-10, and VI-10-20), and post-terpolymer (VIII), respectively, as shown in Figure 13D. However, in the pH12, as illustrated in Figure $13 \mathrm{E}$ the $T_{c^{\prime}}$ s have been observed at $32.8,26.6,19.7$, and $22.3^{\circ} \mathrm{C}$, and $C_{p}$ 's at $33.5,27.8,22.0$, and $23.6{ }^{\circ} \mathrm{C}$ for terpolymers, and post-terpolymer. The dramatic decrease in the transition temperature and cloud point in the alkaline solution is due to the highly intensive hydrophobic effect, which raised by increasing the molar concentration of DMAMVA in the polymer chains, moreover, the hydrophobic groups in guanine have additionally influenced in decreasing the $T_{C}$ and $C_{p}$. Figure 14 illustrated the statistical study of the mean transition temperature $T_{c}{ }_{c} s$ of terpolymers and post-terpolymer. The ANOVA table (overall ANOVA) has reported a p-value of 0.389 , despite, the homogeneity of variances has indicated at 0.05 levels. The overall analysis referred to the population variances is not significantly different.

The Micro-differential scanning calorimetry (Micro-DSC) has been performed in DI water (pH7), and at a heating rate of $5^{\circ} \mathrm{C} / \mathrm{min}$ for recording the $T_{\dot{c}^{\prime}} s$ of different terpolymers VI-10-05, VI-10-10, and VI-10-20 as well as terpolymer-post-guanine VIII as shown in Figure 15; they demonstrated 33.6, 27.5, 19.3, and $23.8^{\circ} \mathrm{C}$, respectively. By comparing these results to be obtained using turbidity, we observed a difference that interpreted to the method used for recording the $T_{c^{\prime}} S$, in the turbidity, it was fixed at the point of inflection, however, the micro-DSC detected at the onset value [55]. Data have also summarized in Table 1.

\section{Conclusion}

The study presented the preparation of a new cationic monomer used in the formation of a dual-responsive thermo-pH terpolymer with functional groups. The polymerization has been achieved with NIPAAm and HEMA as thermo-responsive and hydrophilic functional monomers, respectively. The fabrication methods were implemented in facile methods and all compounds have been investigated and achieved good results regarding their chemical structures. Moreover, the aldehyde functional group was used for the post-polymerization with guanine. The general characterizations of polymers and post-polymer have been discussed; they demonstrated a lower value of the molecular weight, glass transition, and the degree of crystallinity with the higher molar concentration of DMAMVA and by post-guanine as well. The phase separation of polymers and post-polymer was measured in different pH solutions. The $T_{c}$ of polymers in highly acidic conditions showed the highest $T_{c}$ values; the value will decrease at $\mathrm{pH} 7$ and reach the lowest value at the basic solution. These polymers are of interest in our future study in the bio-separation of more biological molecules.

\section{Declarations}


We would like to thank the University of Paderborn.

\section{Conflicts of Interest}

The author declares that there are no conflicts of interest regarding the publication of this paper.

\section{References}

1. Liyuan T, Aaron C. D, David J. C. (2021) Smart Polymers for Microscale Machines. Adv. Funct. Mater. 31:9-2007125. https://doi.org/10.1002/adfm.202007125

2. Banerjee, P., Anas, M., Jana, S. et al. (2020) Recent developments in stimuli-responsive poly(ionic liquid)s. J Polym Res $27,177$. https://doi.org/10.1007/s10965-020-02091-8

3. Jingcheng L, Reddy VS, Jayathilaka W, et al. (2021) Intelligent Polymers. Fibers and Applications. Polymers. $13(9): 1427$. https://doi.org/10.3390/polym13091427

4. Abdelaty, MSA. (2018) Preparation and Characterization of New Environmental Functional Polymers Based on Vanillin and N-isopropylacrylamide for Post Polymerization. J Polym Environ., 26, 636-646. DOl.org/10.1007/s10924-017-0960-2

5. Abdelaty MSA, Kuckling D (2016) Synthesis and Characterization of New Functional Photo Cross-Linkable Smart Polymers Containing Vanillin Derivatives. Gels 2: 1-13. doi:10.3390/gels2010003.

6. Abdelaty, M SA. (2018) Poly(N-isopropylacrylamide-co-2-((diethylamino)methyl)-4 formyl-6-methoxyphenylacrylate) Environmental Functional Copolymers: Synthesis, Characterizations, and Grafting with Amino Acids. Biomolecules, 8, 138. doi:10.3390/biom8040138

7. Liang H, Qiang Z, Xue L, Michael J. S. (2019) Stimuli-responsive polymers for sensing and actuation. Mater. Horiz. 6, $1774-1793$. https://doi.org/10.1039/C9MH00490D

8. Dharmasiri, M.B., Mudiyanselage, T.K. (2021) Thermo-responsive poly(N-isopropyl acrylamide) hydrogel with increased response rate. Polym. Bull. 78, 3183-3198. https://doi.org/10.1007/s00289-020-03270-9

9. Glier, T.E., Vakili, M. \& Trebbin, M. (2020) Microfluidic synthesis of thermo-responsive block copolymer nano-objects via RAFT polymerization. J Polym Res 27, 333. https://doi.org/10.1007/s10965-020-02290-3

10. Sponchioni M, Capasso Palmiero U, Moscatelli D. (2019) Thermo-responsive polymers: Applications of smart materials in drug delivery and tissue engineering. Mater Sci Eng C Mater Biol Appl. 102:589-605. doi: 10.1016/j.msec.2019.04.069.

11. Khalid, I., Ahmad, M., Minhas, M.U. et al. (2018) Preparation and characterization of alginate-PVA-based semi-IPN: controlled release pH-responsive composites. Polym. Bull. 75, 1075-1099. https://doi.org/10.1007/s00289-017-2079-y

12. Pourmoazzen, Z., Bagheri, M., Entezami, A.A. et al. (2013) pH-responsive micelles composed of poly(ethylene glycol) and cholesterol-modified poly(monomethyl itaconate) as a nanocarrier for controlled and targeted release of piroxicam. J Polym Res 20, 295. https://doi.org/10.1007/s10965013-0295-1

13. Azmeera, V., Haldar, U., Roy, S.G. et al. (2021) Block Copolymers of Poly( $\varepsilon$-caprolactone) with pH-Responsive Side-Chain Amino Acid Moieties. J Polym Environ 29, 209-218. https://doi.org/10.1007/s10924-020-01872-y

14. Palanikumar, L., Al-Hosani, S., Kalmouni, M. et al. (2020) pH-responsive high stability polymeric nanoparticles for targeted delivery of anticancer therapeutics. Commun Bio/3, 95. https://doi.org/10.1038/s42003-020-0817-4

15. Lezov, A.A., Lezova, A.A., Vlasov, P.S. et al. (2019) Cationic electrolyte copolymers of diallyldimethylammonium chloride with carboxybetaine 2(diallyl(methyl) ammonio) acetate of various compositions in water solutions of different ionic strengths. J Polym Res 26, 97.

https://doi.org/10.1007/s10965-019-1755-z

16. Fatma Ç, Papatya K, Grace A, Ayse A. et al. (2020) lonic strength-responsive poly(sulfobetaine methacrylate) microgels for fouling removal during ultrafiltration, React Funct Polym. 156: 104738, 1381-5148. https://doi.org/10.1016/j.reactfunctpolym.2020.104738.

17. Chisa N, Akifumi K, and Takashi M. (2017) Mechanical and responsive properties of temperature-responsive gels prepared via atom transfer radical polymerization. Polym. Chem. 8, 6050-6057. https://doi.org/10.1039/C7PY01323J

18. Junhyuk L, Kang H K, Jinwoo K, et al. (2019) Light-Responsive, Shape-Switchable Block Copolymer Particles. Journal of the American Chemical Society. 141 (38), 15348-15355. DOI: 10.1021/jacs.9b07755

19. Olga R, Fabrizio Lo C, Alessandro T (2015) Pressure-responsive mesoscopic structures in room temperature ionic liquids. Phys. Chem. Chem. Phys., 17, 29496-29500. https://doi.org/10.1039/C5CP04682C.

20. Downs, F.G., Lunn, D.J., Booth, M.J. et al. (2020) Multi-responsive hydrogel structures from patterned droplet networks. Nat. Chem. 12, $363-371$. https://doi.org/10.1038/s41557-020-0444-1

21. Huang, W.M., Zhao, Y., Wang, C.C. et al. (2012) Thermo/chemo-responsive shape memory effect in polymers: a sketch of working mechanisms, fundamentals and optimization. J Polym Res 19, 9952. https://doi.org/10.1007/s10965-012-9952-z

22. Abdelaty, M S A. (2021) Trends in the Phase Separation Temperature Optimization of a Functional and Thermo-pH Responsive Terpolymer of Poly (Nisopropylacrylamide-co-N-(2-(dimethylamino)ethyl) Acrylamide-co-vanillin Acrylate). J Polym Environ. https://doi.org/10.1007/s10924-021-02096-4

23. Abdelaty, M.S.A., Kuckling, D. (2021) Altering of lower critical solution temperature of environmentally responsive poly (N-isopropylacrylamide-co-acrylic acid-co-vanillin acrylate) affected by acrylic acid, vanillin acrylate, and post-polymerization modification. Colloid Polym Sci. 299, 1617-1629.

https://doi.org/10.1007/s00396-021-04882-x

Page 8/15 
24. Abdelaty, M.S.A (2018) Environmental Functional Photo-cross-linked Hydrogel Bilayer Thin films From Vanillin (Part 2): Temperature responsive layer A, Functional, Temperature and pH layer B. Polym. Bull., 11, 4837-4858. DOI: 10.1007/s00289-018-2297-y.

25. Abdelaty, MSA (2019) Layer by Layer Photo-Cross-Linked Environmental Functional hydrogel Thin Films Based on Vanillin: Part 3. J Polym Environ. DOI: $10.1007 / \mathrm{s} 10924-019-01421-2$

26. Sanzari, I., Buratti, E., Huang, R. et al. (2020) Poly(N-isopropylacrylamide) based thin microgel films for use in cell culture applications. Sci Rep $10,6126$. https://doi.org/10.1038/s41598-020-63228-9

27. Lanzalaco, Sonia, and Elaine Armelin. (2017) Poly(N-isopropylacrylamide) and Copolymers: A Review on Recent Progresses in Biomedical Applications" Gels 3, 4: 36. https://doi.org/10.3390/gels3040036

28. Pengcheng Ma, Xiaoyan Ma, (2022) High-sensitivity and temperature-controlled switching methanol sensor prepared based on the dual catalysis of copper particles. Talanta, 237, 122888.

https://doi.org/10.1016/j

29. Abdelaty, M SA. (2018) Environmental Functional Photo-Cross-Linked Hydrogel Bilayer Thin Films from Vanillin. J Polym Environ., 26, 2243-2256. DOI: 10.1007/s10924-017-1126-y

30. Abdelaty, M.S.A (2021) Poly(N-isopropylacrylamide-co-2-((diethylamino)methyl)-4-methylphenyl acrylate) thermo-ph responsive copolymer: trend in the lower critical solution temperature optimization of Poly (N-isopropyylacrylamide). J Polym Res 28, 213. https://doi.org/10.1007/s10965-021-02574-2

31. Marzieh N, Mehdi H, Remco F, et al. (2021) LCST polymers with UCST behavior. Soft Matter, 2021, 17, 2132-2141. https://doi.org/10.1039/D0SM01505A

32. Abdelaty, M.S.A (2019) Influence of vanillin acrylate and 4 acetylphenyl acrylate hydrophobic functional monomers on phase separation of $N$ isopropylacrylamide environmental terpolymer: fabrication and characterization. Polym. Bull., DOI 10.1007/s00289-019-02890-0

33. Abdelaty, M.S.A. (2018) Preparation and Characterization of Environmental Functional Poly(Styrene-Co-2-[(Diethylamino)Methyl]-4-Formyl-6-MethoxyPhenyl Acrylate) Copolymers for Amino Acid Post Polymerization. Open Journal of Polymer Chemistry. 8, 41-55.

https://doi.org/10.4236/ojpchem.2018.83005

34. Avraham H, Martin K, and FranÅoise M. W. (2015) Poly(N-isopropylacrylamide) Phase Diagrams: Fifty Years of Research. Angew. Chem. Int. Ed. 54, 15342-15367. https://doi.org/10.1002/anie.201506663

35. Karppi, J., Åkerman, S., Åkerman, K. et al. (2010) Adsorption of metal cations from aqueous solutions onto the pH responsive poly(vinylidene fluoride grafted poly(acrylic acid) (PVDF-PAA) membrane. J Polym Res 17, 71. https://doi.org/10.1007/s10965-009-9291-x

36. Hiremath, J.N., Vishalakshi, B. (2015) Evaluation of a pH-responsive guar gum-based hydrogel as adsorbent for cationic dyes: kinetic and modelling study. Polym. Bull. 72, 3063-3081. https://doi.org/10.1007/s00289-015-1453-x

37. Patil, A.S., Gadad, A.P., Hiremath, R.D. et al. (2018) Exploration of the Effect of Chitosan and Crosslinking Agent Concentration on the Properties of Dual Responsive Chitosan-g-Poly (N-Isopropylacrylamide) Co-polymeric Particles. J Polym Environ 26, 596-606. https://doi.org/10.1007/s10924-017-0971-z

38. Abdelaty, M S A. (2021) a facile Method for the Preparation of Hydrophilic-Hydrophobic Functional Thermo-pH Responsive Terpolymers Based on Poly(NIPAAm-co-DMAA-co-DMAMVA) and Post-Polymerization J Polym Environ. DOI: 10.1007/s10924-021-02117-2

39. Abdelaty, M.S.A., and Kuckling D. (2018) Poly (N-Isopropyl Acrylamide-Co-Vanillin Acrylate) Dual Responsive Functional Copolymers for Grafting Biomolecules by Schiff's Base Click Reaction. Open Journal of Organic Polymer Materials. 8,15-32. DOI: 10.4236/ojopm.2018.82002

40. Kyobum K, William C.W. C, Yunhoe H, Yadong W (2016) Polycations and their biomedical applications, Prog. Polym. Sci, 60, 18-50. https://doi.org/10.1016/j.progpolymsci.2016.05.004.

41. Ke W, Zefeng S, Chonggao L, Wangqing Z (2016) RAFT synthesis of triply responsive poly[N-[2-(dialkylamino)ethyl]acrylamide]s and their N-substitute determined response. Polym. Chem., 2016, 7, 3423-3433. https://doi.org/10.1039/C6PY00526H

42. Najafipour, A., Mahdavian, A.R., Aliabadi, H.S. et al. (2020) Dual thermo- and pH-responsive poly(N-isopropylacrylamide-co-(2-dimethylamino) ethyl methacrylate)-g-PEG nanoparticle system and its potential in controlled drug release. Polym. Bull. 77, 3129-3142. https://doi.org/10.1007/s00289-01902895-9

43. Abdelaty, MSA and Kuckling, D (2016) Synthesis and Characterization of New Functional Photo Cross-Linkable Smart Polymers Containing Vanillin Derivatives. Gels, 2: 1-13. DOI:10.3390/gels2010003

44. Abdelaty, M SA. (2018) Environmental Functional Photo-Cross-Linked Hydrogel Bilayer Thin Films from Vanillin. J Polym Environ. 26, 2243-2256. DOI: 10.1007/s10924-017-1126-y

45. Annika H, Juan M. G, Gabriel S. L. (2018) Use of pH Gradients in Responsive Polymer Hydrogels for the Separation and Localization of Proteins from Binary Mixtures. Macromolecules, 51 (20), 8205-8216. DOI: 10.1021/acs.macromol.8b01876

46. Monica L. O, Jeffrey M. T, Seamus D. J, et al. (2019) Tuning PNIPAm self-assembly and thermoresponse: roles of hydrophobic end-groups and hydrophilic comonomer. Polym. Chem., 2019,10, 3469-3479. https://doi.org/10.1039/C9PY00180H

47. Yihang C, Shiming Z, Qingyu C, et al. (2020) Microengineered poly(HEMA) hydrogels for wearable contact lens biosensing. Lab Chip, 20, $4205-4214$. DOI https://doi.org/10.1039/D0LC00446D

48. Lombello, C.B., Malmonge, S.M., Wada, M.L.F. (2000) PolyHEMA and polyHEMA-poly(MMA-co-AA) as substrates for culturing Vero cells. Journal of Materials Science: Materials in Medicine, 11, 541-546. https://doi.org/10.1023/A:1008915801187 
49. Kim, S.; Shin, B.H.; Yang, C.; et al. (2018) Development of Poly(HEMA-Am) Polymer Hydrogel Filler for Soft Tissue Reconstruction by Facile Polymerization. Polymers, 10, 772. https://doi.org/10.3390/polym10070772

50. Cadotte AJ, DeMarse TB. (2005) Poly-HEMA as a drug delivery device for in vitro neural networks on micro-electrode arrays. J Neural Eng. 2(4):114-22. doi: 10.1088/1741-2560/2/4/007.

51. Tran M Q, Masaru Y, Yasuyuki M, Toshiaki D, (2012) Poly(N-isopropylacrylamide-co-hydroxyethyl methacrylate) graft copolymers and their application as carriers for drug delivery system. J. Appl. Polym. Sci. 4, 2368-2376. https://doi.org/10.1002/app.34821

52. Villa C, Martello F, Erratico S, et al. Torrente Y. (2017) P(NIPAAM-co-HEMA) thermoresponsive hydrogels: an alternative approach for muscle cell sheet engineering. J Tissue Eng Regen Med. 11(1):187-196. doi: 10.1002/term.1898.

53. Gehong S, Tao Z, Xifei L, et al (2017) Micro-dynamics mechanism of the phase transition behavior of poly(N-isopropylacrylamide-co-2-hydroxyethyl methacrylate) hydrogels revealed by two-dimensional correlation spectroscopy. Polym. Chem., 8, 865-878. https://doi.org/10.1039/C6PY01935H

54. Ignace H, Johan B, Frans Van C. (1990) Effect of guanine nucleotides on the hydrophobic interaction of tubulin. Biochemistry, 29, 21, 5160-5165. https://doi.org/10.1021/bi00473a023

55. H. M. Ng, Norshahirah, M. S, Fatin S O, et al. (2018) Thermogravimetric Analysis of Polymers. Encyclopedia of Polymer Science and Technology https://doi.org/10.1002/0471440264.pst667

\section{Figures}

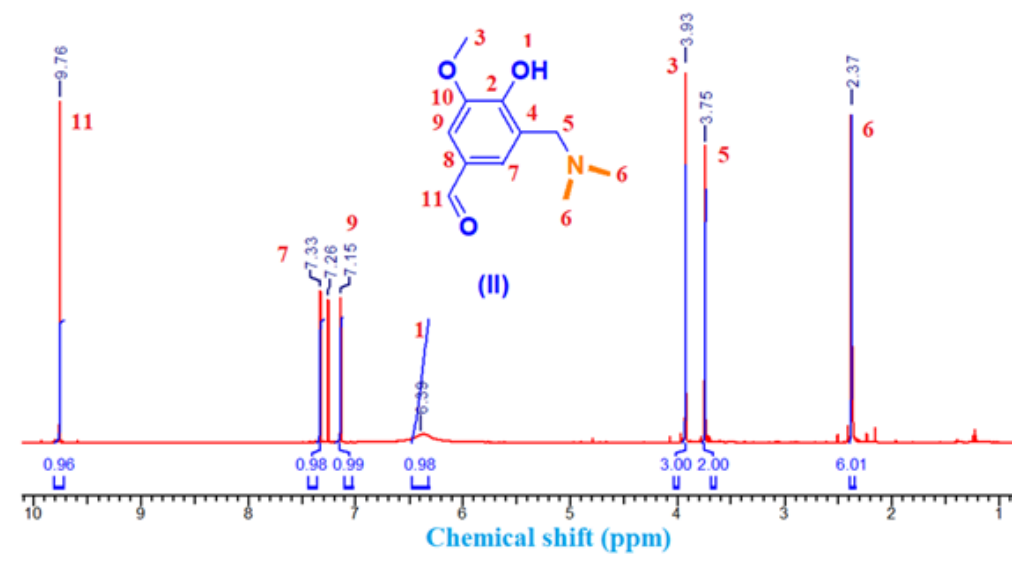

Figure 1

1H NMR spectra (CDCl3) of 3-((dimethylamino)methyl)-4-hydroxy-5-methoxy-benzaldehyde DMAMV(II) (step 1)

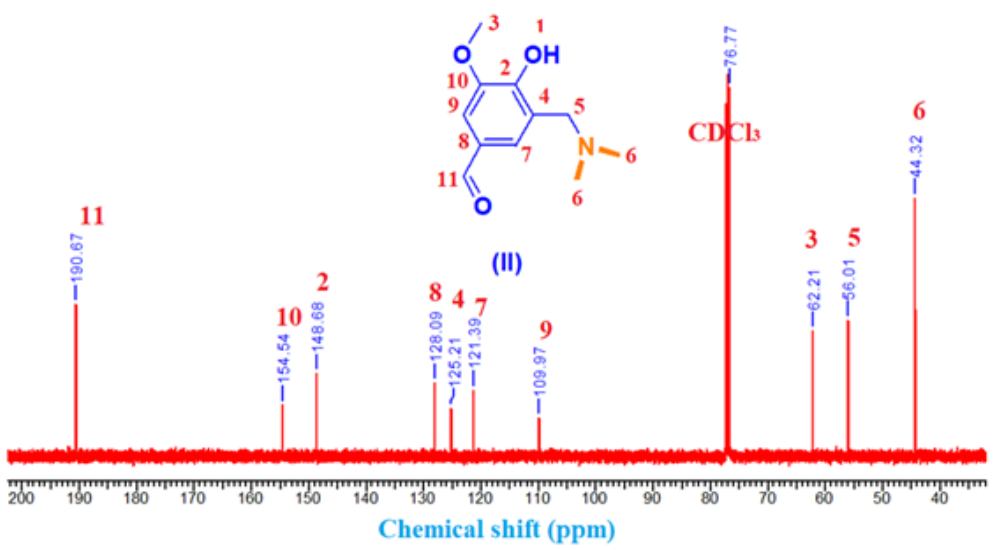

\section{Figure 2}

13C NMR spectra (CDCl3) of 3-((dimethylamino)methyl)-4-hydroxy-5-methoxy-benzaldehyde DMAMV(II) (step 1) 


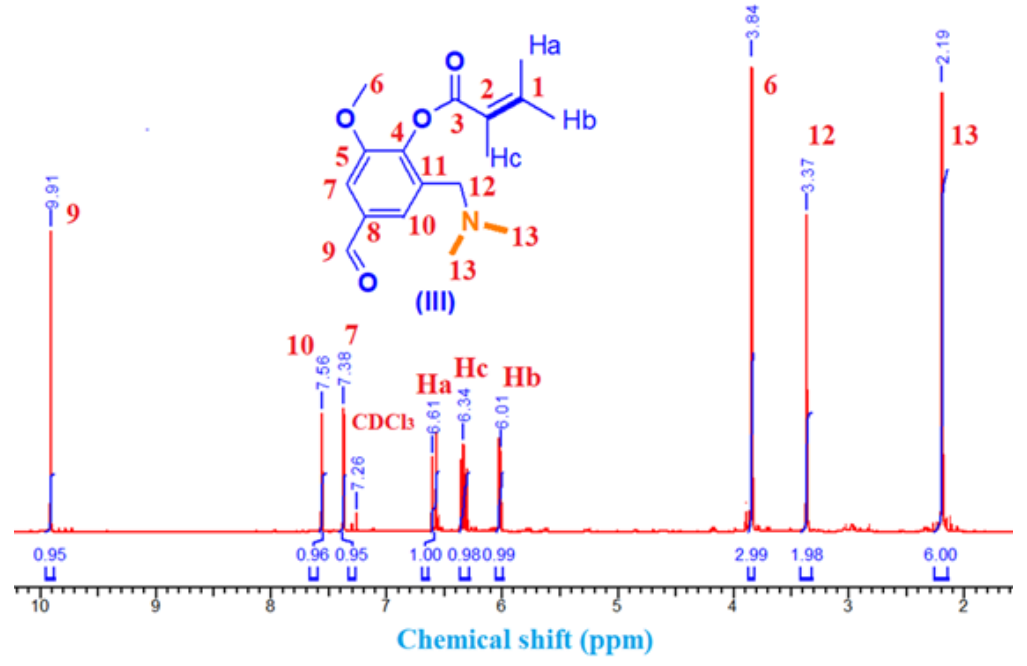

Figure 3

1H NMR spectra (CDCl3) of 2-((dimethylamino)methyl)-4-formyl-6-methoxyphenyl acrylate DMAMVA(II) (step 2)

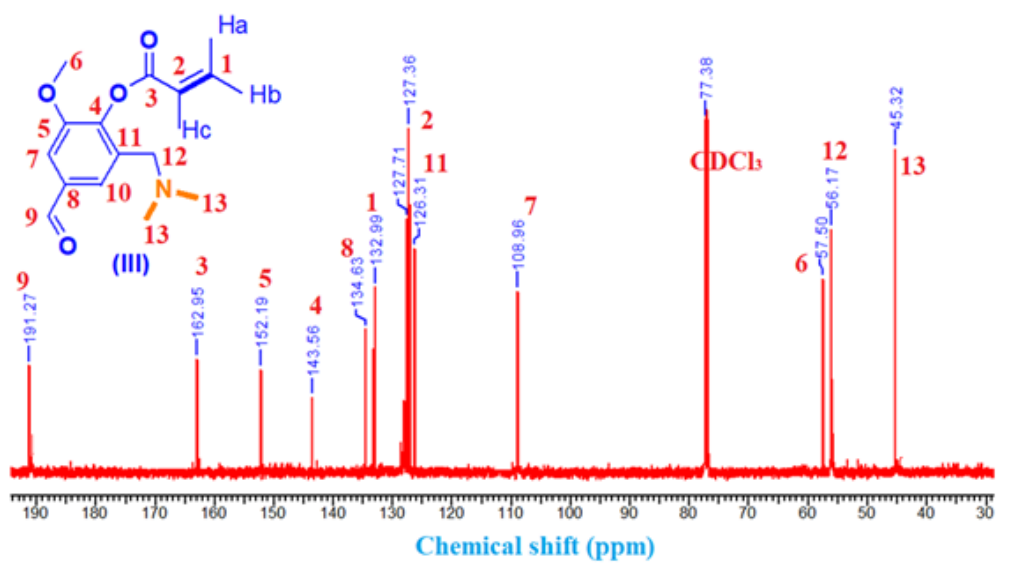

\section{Figure 4}

13C NMR spectra (CDCl3) of 2-((dimethylamino)methyl)-4-formyl-6-methoxyphenyl acrylate DMAMVA (II) (step 2)
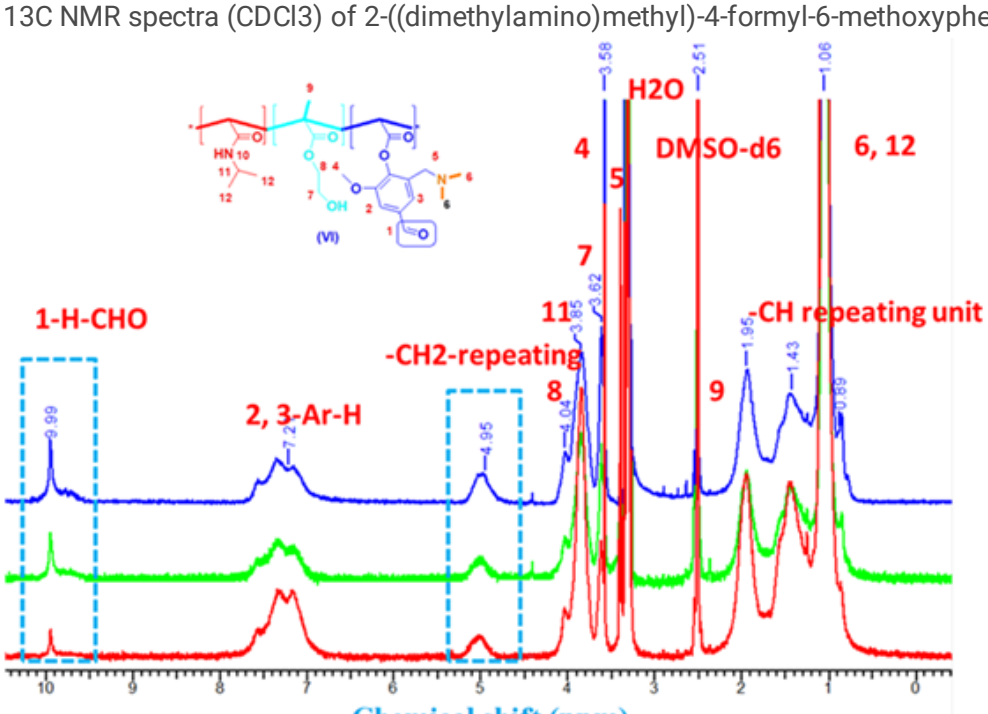

\section{Figure 5}

1H NMR spectrum (DMSO-d6) of poly(NIPAAm-co-HEMA-co-DMAMVA) terpolymer with 10 mol\% of HEMA and 5, 10 and 20 mol\% of DMAMVA. 


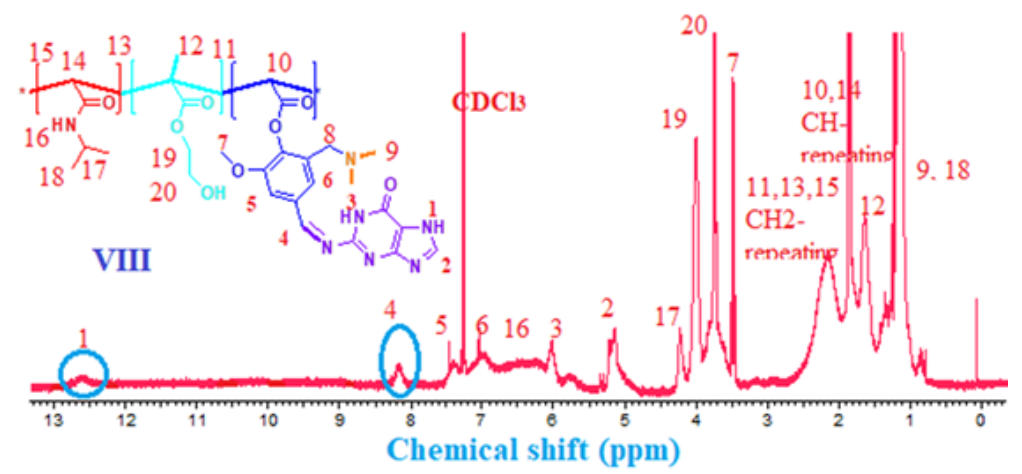

Figure 6

1H NMR spectrum (CDCl3) of poly(NIPAAm-co-HEMA-co-DMAMVA)-post-guanine (VIII)

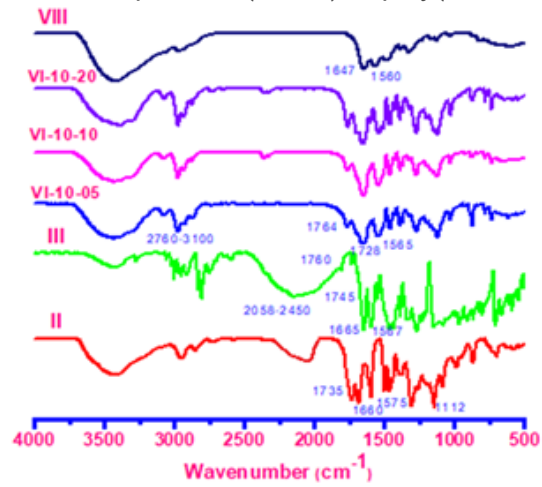

Figure 7

FT IR spectra of monomer II and III, terpolymer VI-10-05, VI-10-10, VI-10-20 and post-terpolymer VIII

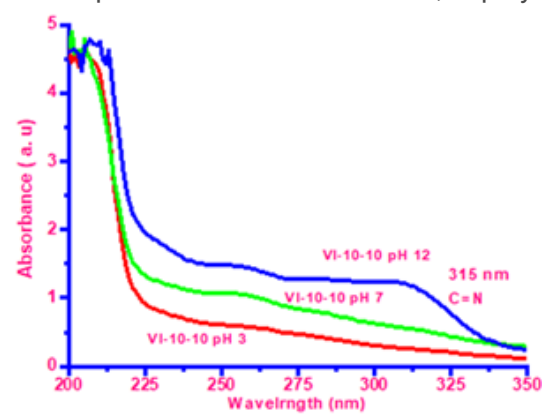

Figure 8

UV-VIS-spectroscopy of poly(NIPAAm-co-HEMA-co-DMAMVA)-post-guanine (VIII) and the formation of imine group at different pH3, pH7 and pH12 solutions

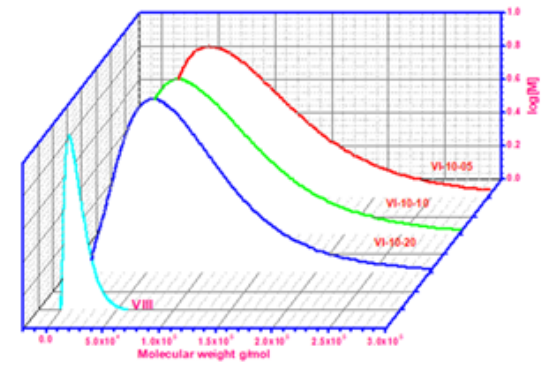

Figure 9

GPC chromatograms of terpolymers (VI-10-05, VI-10-10 and VI-10-20) and post-terpolymer (VIII) 


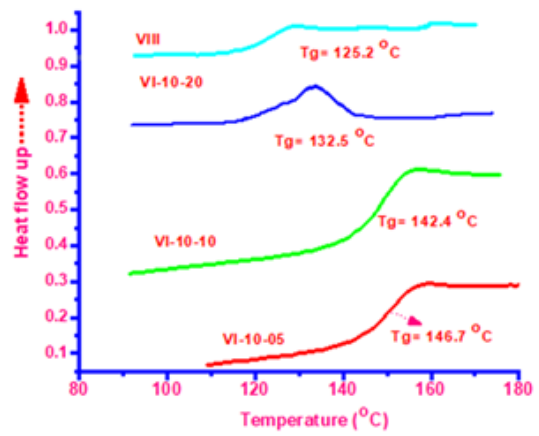

Figure 10

Differential scanning calorimetry (DSC) the diffractogram of the glass transition temperature Tg of terpolymers and post-terpolymer.
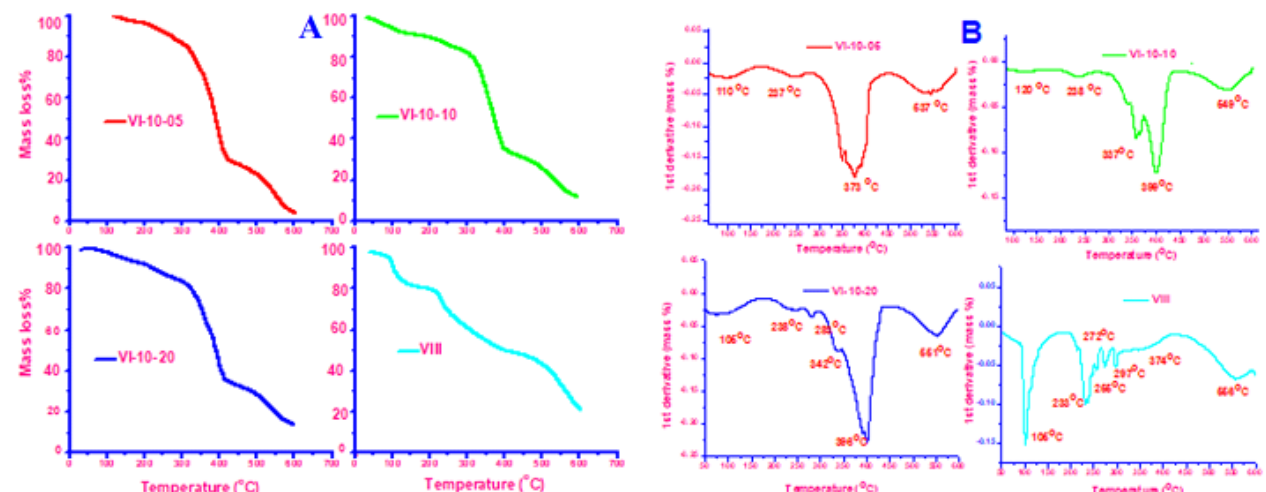

Figure 11

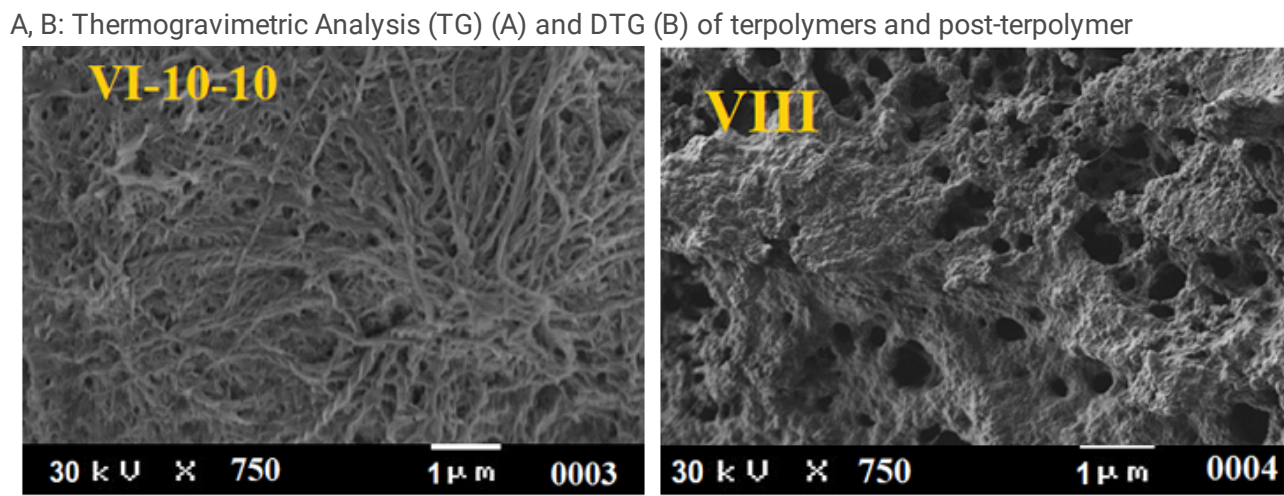

\section{Figure 12}

SEM for terpolymer VI-10-10 and post-terpolymer VIII at a magnification of 750x 

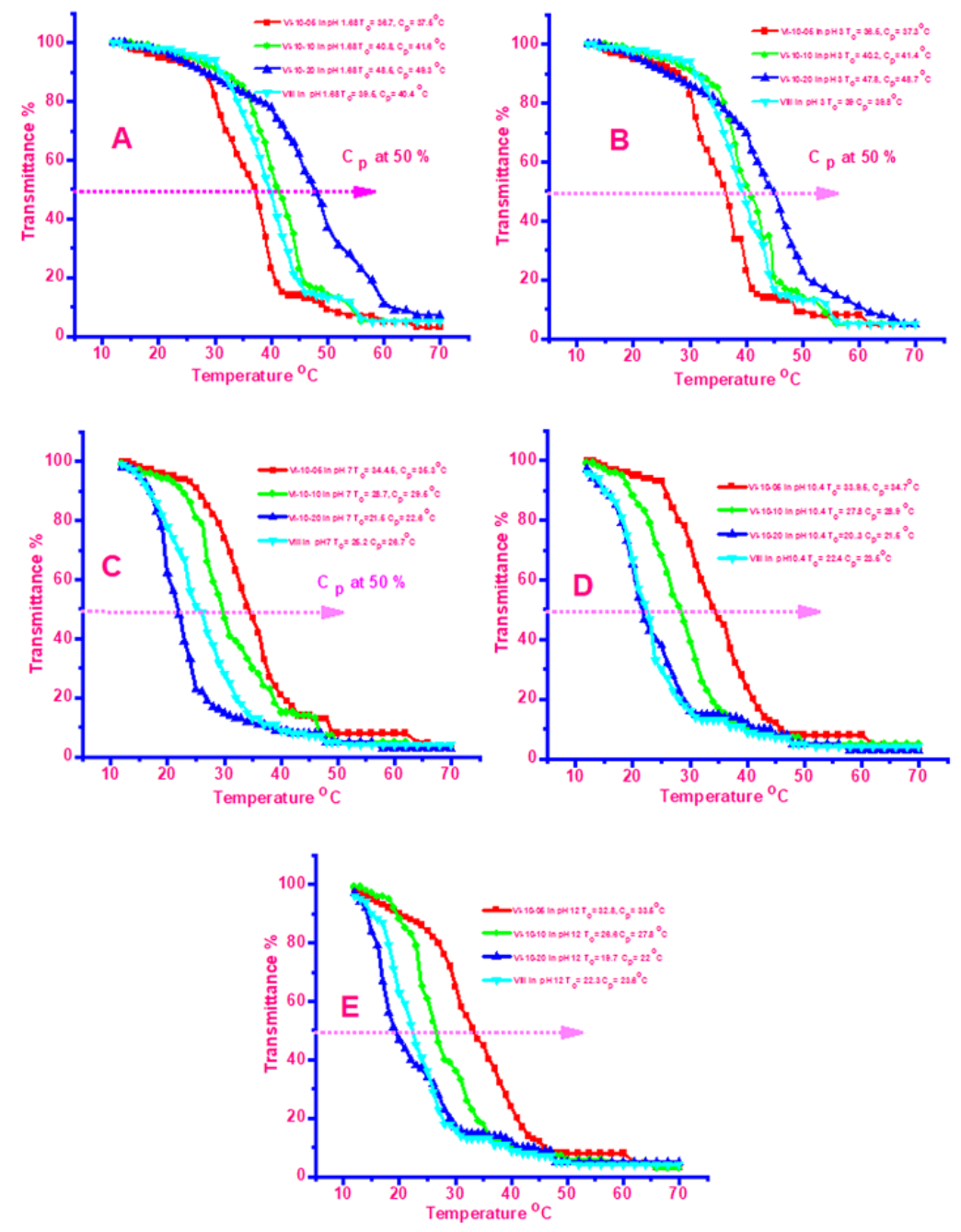

\section{Figure 13}

A-E: The change in transmittance with temperature for Tc,s of Poly (NIPAAm-co-HEMA-co-DMAMVA) VI-10-05, VI-10-10, and VI-10-20 and Poly (NIPAAm-coHEMA-co-DMAMVA)-post-guanine VIII in pH1.68, pH3, pH7, pH10.4 and pH12 using UV-VIS Spectroscopy for 1 wt\% of polymer solution.

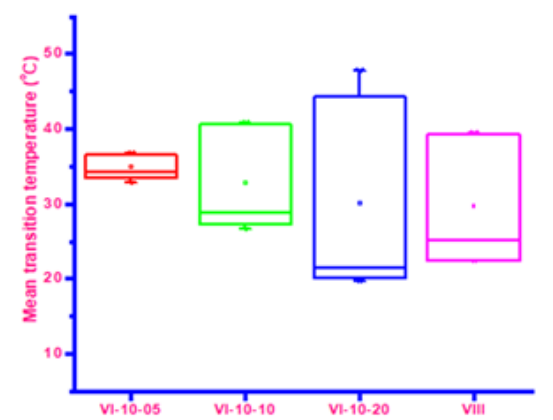

Figure 14

ANOVA statistical test for the significant difference of the mean transition temperature Tc of terpolymers and post-terpolymers 


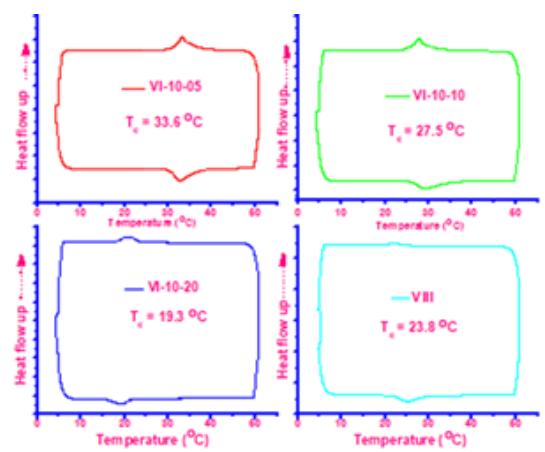

Figure 15

Micro-DSC differactigram for the lower critical solution temperature or the phase transition temperature Tc of terpolymers and post-terpolymer solutions in DI H2O 